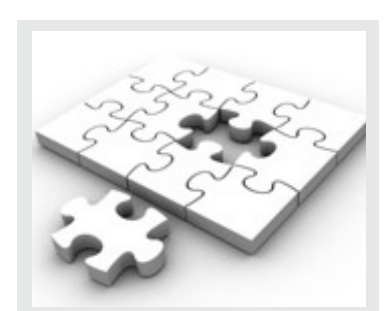

In an effort to facilitate the selection of appropriate peer reviewers for Reading $\mathcal{E}$ Writing, we ask that you take a moment to update your electronic portfolio on http:/ / www.rw.org.za for our files, allowing us better access to your areas of interest and expertise, in order to match reviewers with submitted manuscripts.

If you would like to become a reviewer, please visit the journal website and register as a reviewer.

To access your details on the website, you will need to follow these steps:

1. Log into the online journal at http://www. rw.org.za

2. In your 'user home' [http://www.rw.org.za/ index.php/rw/user] select 'edit my profile' under the heading 'my account' and insert all relevant details, bio statement and reviewing interest.

3. It is good practice as a reviewer to update your personal details regularly to ensure contact with you throughout your professional term as reviewer to Reading $\mathcal{E}$ Writing.

Please do not hesitate to contact us if you require assistance in performing this task.

Publisher: publishing@aosis.co.za

Tel: +27219752602

Fax: +27219754635

\section{Acknowledgement to reviewers}

The editorial team of Reading $\mathcal{E}$ Writing recognises the value and importance of the peer reviewer in the overall publication process - not only in shaping the individual manuscript, but also in shaping the credibility and reputation of our journal.

We are committed to the timely publication of all original, innovative contributions submitted for publication. As such, the identification and selection of reviewers who have expertise and interest in the topics appropriate to each manuscript are essential elements in ensuring a timely, productive peer review process.

We would like to take this opportunity to thank all of those who provided scientific and logistical support for this issue of the Reading $\mathcal{E}$ Writing:
Agnes Chigona
Andre Steenkamp
Arua E. Arua
Berit G. Lundgren
Brenda Spencer
Bulelwa Makena
Candice Livingston
Catherine Kell
Chaka Chaka
Clare Verbeek
Dan Kasule
Daniella Gachago
Denise M. Allen
Douglas Fisher
Sharan Badiger
Elizabeth G. Seeco
Eileen M. Scheckle
Eleni Griva
Elizabeth Pretorius
Elsemieke Wishart
Hanlie Dippenaar
Jørgen E. Christensen
Jacob W. Alant
Jacqui Dornbrack
Janet L. Condy
Jay Blanchard
John W. Foncha
Johnson L. Rose
Judith Mutemeri
Kamal H. Soureshjani

\author{
Karen Roux \\ Katherine E. Arbuckle \\ Kathryn Au \\ Kelly McNeal \\ Ketsitlile Lone \\ Kristin van der Merwe \\ Laura M. Drennan \\ Laura Dison \\ Lisa Zimmerman \\ Lorna Dreyer \\ Louise Olivier \\ Madeleyi Mbelani \\ Margaret A. Hill \\ Maria d.C.L. Gomes \\ Muchativugwa Hove \\ Mzwamadoda P. Cekiso \\ Naomi A. Boakye \\ Peter Plüddemann \\ Peter Rule \\ Restytuta Nalyazi \\ Robin Irey \\ Rose-Marie McCabe \\ Sandra J. Land \\ Sarah Howie \\ Stanley W. Theron \\ Sydney F. Maluleke \\ Titi J. Fola-Adebayo \\ Uju C. Ukwuoma \\ Vasanthie Padayachee \\ Wilfred T. Molotja
}

We appreciate the time taken to perform your review successfully. 